\title{
Sustainable business models in the context of innovation
}

\author{
Anna Pilarczyk ${ }^{1, *}$ \\ ${ }^{1}$ The John Paul II Catholic University of Lublin, Enterprise Management Department, \\ 14 Al. Racławickie. St., 20-950 Lublin, Poland
}

\begin{abstract}
This article concerns the relatively new issue of business model present in science for 20 years. A systematic literature review was carried out for the years 2012-2018. In so-doing through additional defining criteria: type of document - article and topic - business model innovation, apart from the main slogan - sustainable business model, 84 articles were identified, out of which 24 documents were selected for the analysis. The study has been divided into two parts, the first discusses the theoretical aspects related to the tools used for designing sustainable business models, as well as the relationship between value creation and innovation. In the second part of the study, the issue of sustainable development was analyzed within selected sectors of the food and energy industry. The article aims to present current knowledge on sustainable business models in the context of innovation in relation to selected industries.
\end{abstract}

\section{Introduction}

Many excessive phenomena - the over-exploitation of renewable and non-renewable natural resources, rapid climate change and increasing pollution levels - result from the unsustainable development that takes place at the expense of the natural environment. From the point of view of business management as well as general economics, resource management and their availability play an important role. In our societies, lifestyle development is guided by the noble motives of improving quality of life (i.e. the fight against poverty and the improvement of infrastructure). Herein, the natural environment plays a subordinate role to the entire economy and the planned profits of individual organizations and states. It can thus be said that the role of the natural environment as a guarantor of the survival of present and future generations has been lost in the primacy of money-making and ever-growing competition and consumption. As J. Sun et al. have noticed: the environment is not static or passive, but is an agent within the interactive, contextual ecosystem and should be clearly understood as such [1].

The attempt to find redress to the world-wide ever-growing problem of unsustainable industrial and social development has resulted in the document: Agenda for Sustainable Development by 2030, by the United Nations. This document proffers 17 sustainable goals, such as enhancing the quality of education, eliminating hunger, providing good health-care

\footnotetext{
*Corresponding author: apilarczyk@kul.pl
} 
and clean environments, creating pathways to renewable energy as well as green industrial practices, putting in place innovation business practices and developing infrastructure, sustainable consumption and production [2]. These mentioned objectives are a counter to poverty, as well as a means of ensuring ever-continuous prosperity while protecting the natural environment. Accordingly, the features of a sustainable economy include system that:

- encourages the minimising of consumption, or imposes personal and institutional caps or quotas on energy, goods, water, etc.,

- $\quad$ is designed to maximise societal and environmental benefit, rather than prioritising economic growth,

- $\quad$ is closed-loop - where nothing is allowed to be wasted or discarded into the environment which can be reused, repaired, and remade in preference to recycling,

- emphasize delivery of functionality and experience, rather than product ownership,

- $\quad$ is designed to provide fulfilling, rewarding work experiences for all, and which enhance human creativity/skills,

- $\quad$ is built on collaboration and sharing, rather than aggressive competition [3].

Both the Agenda for Sustainable Development adopted in 2015, as well as the features of a sustainable economy as listed, mingle within the framework of the theory of sustainable development. This last is understood as: an alternative path that can grant low-carbon and climate-resilient development, substantial improve resource efficiency, healthy and more resilient ecosystems, social inclusion and greater economic opportunities and social justice particularly for the poor who depend strongly on the environment for their livelihoods, healthiness and well-being [4].

In the quoted definition, one can see an attempt to reconcile all the important dimensions related to human life, including social justice, health and prosperity - with a functioning ecosystem. Secondly, the analyzed concept has a complementary and holistic character. In the face of current trends and changes, the managers of the organization are forced to modify and adapt the company to the growing expectations of the current trend if they want to stay in business. This situation entails the need to introduce innovation. Hence, in this difficult task of redefining the organization, trail-blazing sustainable business models have been posited and put into practice. Such models are understood as business models that create competitive advantage through superior customer value and contribute to the sustainable development of the company and society" [5].

The topic of sustainable business models was chosen for an analysis within this study due to, firstly, the important role it plays both in science and practice. Secondly, the mentioned issue is a specific tool allowing the possibility to adapt to the changes taking place and to meet with growing expectations.

The aim of the article is to present current knowledge on the subject. A systematic review of literature consisted of the following stages: defining the purpose of the study, selecting the basic literature, selecting publications, analyzing the content and presenting the conclusions [6]. In the second stage of the literature review, a total of 84 articles were identified for the years 2012-2018, through the utilization of the following criteria: main and additional password - business model, innovation and sustainable business model, type of document article. Via the analysis of the content of the articles, 24 bibliographic items were eventually selected for the purposes of this study.

\section{Sustainable Business Models (SBM) and their archetypes}

Sustainable business models (SBMs) were created as a result of the evolution of business models. In the literature on the subject, it is possible to find many different definitions of the basic concept of business modelling, but most are based on two pillars, i.e. business models 
perceived as a tool and as a way of doing business. The second aforementioned is connected with the concept of creating, delivering and capturing values.

Business models (BMs) are understood as being conceptual tools to help understand how a firm does business and can be used for analysis, comparison and performance assessment, management, communication and innovation [3]. Beattie and Smith consider this perception of business models as a holistic, whereas Magretta, Osterwalder and Pigneur point towards it holding the logical aspects of properly running a business. Another definition that fits in with the views quoted is the business model definition developed by Teece, in the light of which, a BM is understood as the organisational and financial 'architecture' of a business and includes implicit assumptions about customers, their needs, and the behaviour of revenues, costs and competitors [3]. Accordingly, the components of this include, among others: product/service offering, customer segments, customer relationships, activities, resources, partners, distribution channels, cost structure and revenue model [3].

V. K. Ranjith draws attention to the strategic resources and dynamic process [7]. In turn, Timmers, in one of the first definitions of business models put forward drew attention to the activities of various business actors and the roles they play. The continuation of such thinking is found in the works of other authors as Doubosson-Torbay et al. and Mahadevan and Schafer et al.[8].

The second way of perceiving business models focuses on values, in particular: the essence of a BM is in defining the manner by which the enterprise delivers value to customers, entices customers to pay for value, and converts those payments to profit. It thus reflects management's hypothesis about what customers want, how they want it, and how the enterprise can organize to best meet those needs, get paid for doing so, and make a profit [8].

R. Boloslavo gives a comprehensive answer to the questioned need for business model, namely that business models allows the visualization, testing and correction of strategic decisions. This translates into an easier implementation process and in improved organizational efficiency [8]. By practicing the use of business models, companies are able to define their competitive strategy by means of proffering marketable products or service projects or through diminishing production costs, and defining those features that distinguish that company from its competitors.

The definition of sustainable business models does not diverge significantly from the basic concept of business models. All the important elements - along with added values for sustainable development - are reflected in a definition of sustainable models that in practice means creating a competitive advantage through superior customer value and [which] contributes to the sustainable development of the company and society [3]. As L. Piscicelli points out that sustainable business models, apart from their potential to create competitive advantages while at the same time providing social and environmental benefits, are instruments accelerating the necessary changes in this area [9]. A similar point of view is represented by T.T. Sousa-Zomer, who considers sustainable business models as important levers for change[10].

A sustainable business model (SMB) can also be considered through the prism of values, in particular, through value propositions, value creation through delivery system innovation, and through value capture. The first element of the afore-mentioned SMB is associated with the organization's economic, environmental and social added values and long term goals. A value creation and delivery system in the context of SMB includes diverse sustainable areas of organization, for example, operations management, reporting, supply chain management and work design. The last component of SBM lies in dominating varied forms of nonmonetary value capture. In practice, the organization strives to achieve economic value, while simultaneously taking the initiative for generating or maintaining positive social and natural environments [11]. Conceptualizing a sustainable value proposition is a critical task in 
sustainable business model innovation, because it requires understanding and managing several needs and objectives across a network of multiple stakeholders in order to create shared value [12].

From the point of view of the problems cited at the beginning of this article which result from unsustainable development, a visible change consists first in the lack of favoritism towards shareholders alone and, secondly, a change in the perception of the role of the environment from the servile to the protected. In the subject literature, key features of sustainable business models have thus been defined. Herein, a sustainable BM:

- defines its purpose from simultaneous address of economic, environmental and social aspects,

- uses a triple bottom line approach in measuring performance,

- takes into account the needs of several stakeholders and does not favour only the shareholders,

- treats Nature as a stakeholder and promotes environmental stewardship,

- encompasses the broader system, as well as the narrow firm level perspectives [8].

A significant facilitation in the analysis and conduct of research on sustainable business models is found in the SBM archetype classification developed by N.M. P. Bocken et al. These archetypes make reference to the classical elements of business model innovation: technological, social and organisational. With regard to the technological dimension of SBMs, it is possible to distinguish the following archetype fundamentals:

- maximise material and energy efficiency through following low carbon manufacturing and solutions, or reducing total number of products required,

- create value from waste via the circular economy or industrial symbiosis and extended producer responsibility,

- $\quad$ substitute with renewable and natural processes - with green chemistry, zero emissions initiatives [3].

These SBM archetypes can be summarized as ways to increase production with reduced resource use and reduced pollution and resource consumption.

In the social dimension of innovation, N.M.P. Bocken et al. defines three more archetype basics:

- deliver functionality rather than ownership (i.e. product and use-oriented Product Service - system or Private Finance Initiative),

- adopt a stewardship role (with biodiversity protection, ethical trade, choice editing by retailers),

- encourage sufficiency (by consumer education, product longevity, responsible product offerings, distribution and promotion) [3].

The aforementioned archetypal basics are ways of proffering services that satisfy users' needs without having to own physical products, and are means of providing solutions that actively seek to reduce consumption and production but simultaneously proactively engage with all stakeholders to ensure their long-term health and well-being.

The last dimension of innovation includes two archetypes:

- Repurpose for sociological/ environmental purposes (i.e. hybrid business, social enterprises, social and biodiversity regeneration initiatives) - herein, the emphasis is on the integration of the local community instead of maximisation of shareholder value,

- Develop scale-up solutions by means of open innovation platforms, crowd sourcing and funding as a continuation of the previous archetype [3].

The discussed archetypes have made their appearance in many articles $[8,9,11,13,14]$.

When analyzing the issue of SBM, it is worth paying attention to the transforming factors of the Product -Service System (PSS) business model that now include aspects of sustainable development. A.P. Barquet et al. (found on a systematic review of literature in the Web of 
Science and Science Direct database) defined 4 sustainability factors for sustainable PSS business model along with 18 sub-factors.

The first element is applying designs for a green environment. This can be achieved through utilizing cleaner technologies, optimizing product lifespan and reducing emissions, materials and energy use (in other words concepts of sustainable development). The second factor concerns the identification of economic value through increasing the range of offered services, providing economic incentives to recover products and finally achieving cost saving from reduced material use. The third factor involves changing customer behavior through educating, engaging and increasing their satisfaction. The goal of the next factor of transforming the classic PSS business model to more sustainable practices is to undertake activity for the benefit of social well-being through empowering local economies, broadening access to proper nutrition and health-care services and improving working conditions. Such practices include integrating people's need into the corporate structure. The last PSS sustainability factor is to introduce green innovations at various levels (which in its essence may concern processes, value chain, products-services innovation and ICT technologies).

In analyzing the discussed factors, it can be concluded that two of the aforementioned concern two key entities: clients and employees. Undertaking an attempt to influence client behavior may facilitate the adjustment of two factors - design for best environmental practices and identify economic value to the requirements arising from the discussed concept. For organizations, it may be problematic to educate clients, but on the other hand, it is an opportunity to establish cooperation between universities and business partners. L. Ivascu et al. in her article, discusses strategic directions for successful collaboration between the mentioned entities. In the authors' opinion, the transfer of knowledge plays an important role in innovation and growth. Herein, universities can be attractive partners for cooperation due to their holding a well-defined structure that supports research projects, and having strengths in developing new partnerships, supporting existing projects and launching new opportunities [15].

In turn, activities aimed at improving the conditions and quality of employee work practices and environment can contribute to the implementation of various improvements and innovations within the organization which simultaneously affect the remaining 4 mentioned sustainability factors [16].

Detailed knowledge of the sustainable business model will bring many benefits. First of all, the concept of sustainable development will gain a specific tool facilitating the implementation of an approach that protects a wider group of an organization's stakeholders, while simultaneously including in this group the natural environment. Secondly, from the SBM's point of view, it can be considered as a relatively new research area, requiring further research, the more so as, as rightly noted by J.C. de Man and J.O. Strandhagen, the sustainable business model is not finished. i.e. there is no definitive design on how to run a sustainable company [17].

\section{Examples of tools for designing sustainable business models}

This part of the article will discuss the tools used in the design of sustainable business models.

The first tool with importance from the point of view of the discussed issue is the Triple Layer Business Model Canvas (TLBM). This integrates all the important values of sustainable development. It was advanced in 2010, by Osterwalder and Pigneur and is built upon another less sophisticated tool for innovation support (the Business Model Canvas).

An unquestionable advantage of TLBM is the combination of business model innovation and sustainable business model in order to support changes aimed at meeting the challenges of the present times while taking into account social, economic and environmental values. 
The creators of this tool note that TLBM helps to better understand the relationship between the organization's activities and their impact on the environment and greater society. In addition, it facilitates the assimilation of innovative activities which are often relatively isolated from the system implemented in the organization.

During the development of the discussed tool, two new canvas layers were added. These explore environmental and social value creation. As noted by Lozano: the TLBMC provides 'horizontal' coherence within each canvas layer for exploring economic, environmental and social value individually and 'vertical' coherence integrating value creation across the three canvas layers [18].

The environmental layer is based on life cycle assessments which, combined with innovation, support competitive advantage in the dimension of proffered product. The mentioned layer consists of the following elements: supplies and out-sourcing, production, materials, functional value, end-of-life, distribution, use-phase, environmental impacts and benefits. The second layer, the social, builds on a stakeholder management approach that explores the business entity's social impact. In this regard, the stakeholder management approach seeks to balance the interests of the business's stakeholders rather than simply seeking maximum gain for the entity itself. Among the elements that make up this layer, it is possible to enumerate local communities, governance, social value, employees, societal culture, scale of outreach, end-users, social impacts and benefits [18]. The author of this tract holds that the composition of the discussed layers is not surprising because they are fully compatible with the concept of sustainable development.

The second helpful tool is designed to facilitate the adaptation of an organization's existing business model to one more sustainable Business Model Building Blocks. It consists of 4 pillars: product, customer interface, infrastructure management and financial aspects. In article, R. Rauter puts forward the following Business Model Building Blocks:

- value proposition (product pillar) - PSS having a strong focus on re-use; generation of sustainable products in the manufacture of which lowered CO2-emissions come about; products which are produced through fair-trade agreements,

- target customer (customer interface pillar)- the product is targeted towards customers that are aware of sustainability-related issues,

- distribution channel relationship (customer interface pillar) - the company explores different ways of distributing products and services - through direct distribution, online shops or distribution partners,

- value configuration (infrastructure management pillar) - partnerships made with suppliers and partners so as to allow for concentration on core competencies,

- core competency (infrastructure management pillar) - concentration placed on core competencies and on organizing all other relevant processes together with partners,

- partner network (infrastructure management pillar) - expressing appreciation for partners by changing relevant wording to that which is inclusive or by talking about partnership instead of competition,

- revenue model (financial aspects pillar) - besides generating revenue, the companies generate additional value by being socially active regionally and locally,

- cost structure (financial aspects pillar) - cost structure is adapted in such a way that suppliers (for example) are able to both fulfil their requirements and make profit [19].

It must be noted that in the third tool (fig. 1) discussed in this paper is that of Amit and Zott who did not intend a reference to significant values from the point of view of sustainable development. Still, nothing prevents us from using this tool to design sustainable business models which relate to best environmental and communal practices.

In accordance with this tool, business models are defined as being the content, structure, and governance of transactions designed so as to create value through the exploitation of 
business opportunities and differentiate among four architectures of an activity systemdesign elements [20].

\begin{tabular}{|c|c|c|c|c|}
\hline \multirow{7}{*}{ 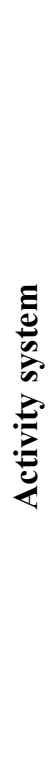 } & \multirow{4}{*}{\multicolumn{2}{|c|}{ 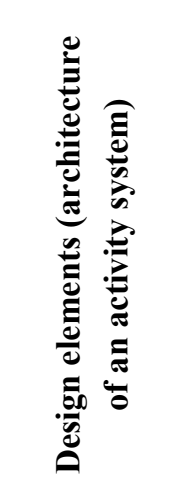 }} & Novelty & $\begin{array}{c}\text { Adopting innovative content, structure or } \\
\text { governance }\end{array}$ \\
\hline & & & Lock-in & $\begin{array}{l}\text { Building in elements to attract and keep } \\
\text { customers }\end{array}$ \\
\hline & & & $\begin{array}{l}\text { Complementari } \\
\text { ties }\end{array}$ & Building activities to generate more value \\
\hline & & & Efficiency & $\begin{array}{l}\text { Reorganizing activities to reduce } \\
\text { transactions costs }\end{array}$ \\
\hline & \multirow{3}{*}{\multicolumn{2}{|c|}{ 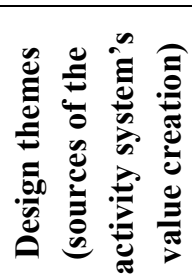 }} & Content & What activities are performed? \\
\hline & & & Structure & $\begin{array}{l}\text { How are the activities linked and } \\
\text { sequenced? }\end{array}$ \\
\hline & & & Governance & Who performs the activities, and where? \\
\hline
\end{tabular}

Fig.1. A business model design tool according to [20].

The author of this tract holds that the tools discussed for the design of sustainable business models may be useful for managers who face the challenge of adapting the operating business model to the needs and expectations of an increasingly popular sustainable development strategy. In addition, along with the growing interest in the research of business models (including those that are sustainable), by so-doing, there will be more specific solutions to facilitate the development, implementation, management and analysis of various types of business models - including those which are sustainable.

\section{Sustainable business models in selected industries}

In the last part of the article, sustainable business models in the energy and food industry will be analyzed.

An interesting case study of the change of the business model as a result of establishing cooperation between organizations in the energy industry was presented in [21]. The analysis concerned 4 companies: GreenEn, Electra and BetaBoiler, SavEn and Local Bank. These entities created a network called 'Network' that aimed at implementing more sustainable operations by reducing energy demand, improving energy efficiency, and producing green energy. Each of the companies forming Network had its role: GreenEn-market support, Electra and BetaBoiler - management expertise and product generation, SavEn-product specialist and Local Bank - financial and business consultancy.

Changes taking place in business models can be analyzed using the basic elements that make up business models. The value proposition that is subject to change herein is in what the participants of Network produce or offer or in how they do so. In the case of BetaBoiler, the value proposition before network participation concerned producing a variety of boilers for diverse customers. On participation in Network, the company ceased production of traditional boiler styles, substituting these with high quality and sustainable boilers. Post 
Network participation, BetaBoiler Company continued to produced high quality boilers suitable for producing energy from renewable sources with minimal environmental impact.

The value capture of the composite entity also changed from the focus on cost in the case of BetaBoiler and GreenEn, and on price leadership to maximise profit (in Electra), as well as on market niche in SavEn, owing to specific competencies, to new arrangements for gaining new customers and increasing margins from the extant market by addressing environmental issues. The activities of the mentioned entities within value creation and delivery include important values for sustainable development [21]. The presented example illustrates the positive changes resulting from the analyzed concept taking into account the interests of all parties, and which were introduced through changes of business model within the selected entities.

The second example concerns the analysis of P.J. Gallo et al. of the business models of four companies operating in the chocolate industry. In their work, they identified an associative sustainable business model that was defined as a subcategory of SBM and business models deeply grounded in associative behaviours and partnerships to create value in the triple bottom line [22]. Based on the results of the analysis, four mentioned companies authors found that partnering, collaboration and cooperatives were essential elements in the business models and were instrumental in addressing sustainability challenges.

The third example concerns sustainable business models in the water sector. Water is a valuable natural resource, and in the face of climate change and population growth, it is necessary to include the concept of sustainable development in this industry. This is especially so in relation to the problem arising from increased consumption of bottled water and, consequently, increased production of plastic waste. Thus, companies operating in this sector face the necessity of adapting their business models to ecologically sustainable approaches. The case study prepared by T.T. Sousa-Zomer and P.A. Cauchik- Miguel is about PSS in the southern region of Brazil. The authors of the article identified the following problems: low water quality, outdated system of water treatment, problems with the water supply network, increasing consumption of bottled water and the low efficiency of the water distribution system. They hold that the introduction of sustainable business models that include the involvement of the private sector and public say can solve these problems together with a maximization of public welfare and social value [10].

In the course of developing their case study, they analyzed the following sustainability aspects between the followed PSS and bottled water use: energy consumption, waste generation, renewable resource misuse, employment of labor, added value health and safety - in the one word, all important dimensions of sustainability development. The study looks at individuals elements of the SBM, and the value proposition of this sustainable business model consist of providing safe and affordable water through the delivery of purified water while including the interests of everyone. Herein, the service provider supplies water at an affordable price (which is in the interest of customers), but at the same time, it profits from water treatment practices and operation. Moreover, by creating a sustainable, safe, functioning public water supply system, the production of plastic waste is limited. The value is created from the integration of the equipment manufacturer, the service provider, and the commercial establishment. The value capture is based on providing good quality water to people who do not have access to it, at prices lower than that of bottled water [10].

The final case study concerns sustainability issues in the mining industry. Here, an analysis of the article topic about the industry's organisational culture is understood as a relationship between the corporation and its internal stakeholders, particularly its employees. In the selected article, the authors also used the four basic BM pillars (product, customer, infrastructure management and financial aspects), which were discussed in the second part of this article [23]. 


\section{Summary}

The impact of sustainable development and business model has been researched by many authors from various parts of the world analyze SMB in the context of various industries, including fashion [24], construction[25], service and energy. This may be a sign of the evergrowing popularity of the diverse types of business models, and because through sustainable business modelling, company managers are able to meet emerging challenges.

Individual companies and entire industries can be analyzed through the value proposition, creating and capturing prism. What is more, even the structure of higher education and research institutes can be defined through applying business models. In addition to the scientific exploration of the discussed issue, the majority of Business Schools offer courses in business model creation [26]. Moreover, the validity of these concepts confirms the UN's strategic and balanced objectives included in the Sustainable Development Agenda until 2030. The mentioned goals to be achieved over the next 12 years will have a significant impact on the operations conducted by the companies. Still, as rightly pointed out by B. Nogalski and T. Falencikowski, business models are at an early stage of recognition [27], and science does not like a vacuum.

\section{References}

1. J. Sun, S. Wu, K. Yang, Business Horizons, 61, 61 (2018)

2. N.M.P. Bocken, S. Short, P. Rana, S. Evans, Journal of Cleaner Production, 65, 42,43, 47-54 (2014)

3. M. Ursache, Procedia Economics and Finance, 15, 1317 (2014)

4. M. Yang, S. Evans, D. Vladimirova, P. Rana, Journal of Cleaner Production, 140, 1795 (2017)

5. W. Czakon (ed.), Podstawy metodologii badań w naukach o zarządzaniu (Wolters Kluwer SA, Warszawa, 2013)

6. V. Ranjith, Procedia Economics and Finance, 37, 204 (2016)

7. R. Biloslavo, C. Bagnoli, D. Edgar, Journal of Cleaner Production, 174, 746-750 (2018)

8. L. Piscicelli, G. Ludden, T. Cooper, Journal of Cleaner Production, 172, 4581 (2018)

9. T.T. Sousa-Zomer, P.A. Cauchick- Miguel, Journal of Cleaner Production, 171, 121$124(2018)$

10. S. Morioka, I. Bolis, S. Evans, M. Carvalho, Journal of Cleaner Production, 167, 725 (2017)

11. B. Baldassarre, G. Calabretta, N.Bocken, T. Jaskiewicz, Journal of Cleaner Production, 147, 177 (2017)

12. P. Ritala, P. Huotari, N. Bocken, L. Albareda, K. Puumalaine, Journal of Cleaner Production, 170, 218, 219 (2018)

13. N. Calvo, O. Villarreal, Journal of Cleaner Production, 191, 27,29 (2018)

14. L. Ivascu, B. Cirjaliu, A. Draghici, Procedia Economics and Finance, 39, 676 (2016)

15. A. Barquet, J.Seidel, G. Seliger, H. Kohl, Procedia CIRP, 47, 437 (2016)

16. J. C. de Man, J. O. Strandhagen, Procedia CIRP, 63, 722 (2017)

17. A. Joyce, R. L. Paquin, Journal of Cleaner Production, 135, 1477 (2016)

18. R. Rauter, J. Jonker, R. J. Baumgartner, Journal of Cleaner Production, 140, 149 (2017)

19. R. Hahn, P. Spieth, I. Ince, Journal of Cleaner Production, 176, 441 (2018)

20. F. Rossignoli, A. Lionzo, Journal of Cleaner Production, 182, 701-702 (2018) 
21. P. J. Gallo, R. Antolin-Lopez, I. Montiel, Journal of Cleaner Production, 174, 906, 915 (2018)

22. L. Bini, M. Bellucci, F. Giunta, Journal of Cleaner Production, 171, 1163-1165 (2018)

23. R. Pal, J. Gander, Journal of Cleaner Production, 184, 253 (2018)

24. I. Palomares-Aguirre, M. Barnett, F. Layrisse, B. W. Husted, Journal of Cleaner Production, 172, 4506-4513 (2018)

25. M. Hoveskog, F. Halila, M. Mattsson, A. Upward, N. Karlsson, Journal of Cleaner Production, 172, 4383-4396 (2018)

26. J. Rokita (ed.), Nowe obszary badań w naukach o zarzadzaniu, (GWSH, Katowice, 2015)

27. www.un.org/sustainabledevelopment/sustainable-development-goals 